\title{
Holocentric chromosomes: convergent evolution, meiotic adaptations, and genomic analysis
}

\author{
Daniël P. Melters • Leocadia V. Paliulis • \\ Ian F. Korf • Simon W. L. Chan
}

Published online: 6 July 2012

(C) Springer Science+Business Media B.V. 2012

\begin{abstract}
In most eukaryotes, the kinetochore protein complex assembles at a single locus termed the centromere to attach chromosomes to spindle microtubules. Holocentric chromosomes have the unusual property of attaching to spindle microtubules along their entire length. Our mechanistic understanding of holocentric chromosome function is derived largely from studies in the nematode Caenorhabditis elegans, but holocentric chromosomes are found over a broad range of animal and plant species. In this review, we describe how holocentricity may be identified through cytological and molecular methods. By surveying the diversity of organisms with holocentric chromosomes, we estimate that the
\end{abstract}

Responsible Editor: Rachel O’Neill and Beth Sullivan.

Electronic supplementary material The online version of this article (doi:10.1007/s10577-012-9292-1) contains

supplementary material, which is available to authorized users.

D. P. Melters · I. F. Korf

Department of Molecular and Cell Biology and Genome Center, University of California,

Davis, CA, USA

D. P. Melters $\cdot$ S. W. L. Chan

Department of Plant Biology, University of California,

Davis, CA, USA

L. V. Paliulis

Biology Department, Bucknell University,

Lewisburg, PA 17837, USA

S. W. L. Chan $(\triangle)$

Howard Hughes Medical Institute,

Chevy Chase, MD, USA

e-mail: srchan@ucdavis.edu trait has arisen at least 13 independent times (four times in plants and at least nine times in animals). Holocentric chromosomes have inherent problems in meiosis because bivalents can attach to spindles in a random fashion. Interestingly, there are several solutions that have evolved to allow accurate meiotic segregation of holocentric chromosomes. Lastly, we describe how extensive genome sequencing and experiments in nonmodel organisms may allow holocentric chromosomes to shed light on general principles of chromosome segregation.

Keywords centromere holocentric $\cdot$ meiosis . phylogeny $\cdot$ tandem repeat $\cdot$ chromosome
Abbreviations
ChIP-seq Chromatin immunoprecipitation followed by sequencing
ChIP-chip Chromatin immunoprecipitation followed by hybridization of isolated DNA to a DNA microarray.
FISH Fluorescent in situ hybridization.
cenH3 Centromere specific histone $\mathrm{H} 3$ variant (CENP-A in humans Cid in Drosophila melanogaster, HCP-3 in Caenorhabditis elegans)

\footnotetext{
"Darwin answers that we must look for imperfections and oddities, because any perfection in organic design or ecology obliterates the paths of history and might have been created as we find it." Stephen J. Gould (1986)
} 


\section{Introduction}

The centromere is the chromosomal locus bound by kinetochore proteins that connect eukaryotic chromosomes to spindle microtubules during cell division. In most eukaryotes, kinetochore proteins assemble at a single location per chromosome. In these "monocentric" chromosomes, the centromere is visible as the primary constriction in large metaphase chromosomes. In select taxa, kinetochore proteins bind along the entire length of the chromosomes and microtubules can attach along most of the poleward facing surface (Dernburg 2001; Maddox et al. 2004; Guerra et al. 2010). First described in cytogenetic experiments dating from 1935 (Schrader 1935), these "holocentric" chromosomes have also been called diffuse-kinetochore chromosomes, holokinetic chromosomes, and polykinetic chromosomes. These differences in nomenclature may reflect the difficulty of distinguishing chromosomes with evenly distributed kinetochore proteins from chromosomes that contain numerous but discrete microtubule-binding sites (White 1973). For the rest of this review, we will use the most common term, i.e., holocentric chromosomes. Although holocentric chromosomes are found in a minority of eukaryotes, their prevalence may be underestimated. Many species are difficult to study cytologically. In addition, there are a large number of uncharacterized insect and nematode species whose phylogenetic position suggest that they should have holocentric chromosomes.

The nematode Caenorhabditis elegans is by far the most well-studied holocentric organism. The function of kinetochore proteins in this organism has been reviewed elsewhere (Dernburg 2001; Maddox et al. 2004). Almost nothing is known about the biology of other holocentric species. The primary goal of this review is to survey the evolution of holocentric chromosomes throughout eukaryotes, highlighting the fact that this property has arisen many independent times. A crucial step in adapting to the holocentric habit is alterations in meiosis, and we describe how the fundamental incompatibility between distributed microtubulebinding sites and crossing-over can be resolved. Lastly, we show how widespread genome sequencing can shed light on the function of holocentric chromosomes.

\section{Identification of holocentric chromosomes}

How can we identify and confirm holocentricity? Ideally, several criteria should be met. In species with large chromosomes, cytogenetic methods are valuable and are applicable to any organism in which individual mitotic or meiotic chromosomes can be observed. First, all chromosomes in a mitotic metaphase spread must lack a primary constriction [a classic hallmark of (sub-)metacentric chromosomes] (Fig. 1a). Second, during mitotic anaphase, the sister chromatids must migrate in parallel to the spindle poles, in contrast to monocentric species in which pulling forces are exerted on a single chromosomal point and chromosome arms trail behind (Fig. 1b). These two criteria are historically the most common methods used to identify holocentric species.

Some species are amenable to detailed cytogenetic manipulations that can diagnose holocentricity more definitively. If a holocentric chromosome is fragmented, each individual fragment retains centromere activity and can segregate to the poles (Fig. 1c). Chromosomes can be broken by X-ray irradiation (Hughes-Schrader and Schrader 1961), or more precisely by laser dissection (Fuková et al. 2007). Chromosomal fragments must persist after breakage, and micronuclei resulting from a failure to segregate chromosome fragments should not be observed. One problem of chromosome breakage techniques is that DNA damage response pathways can induce cellcycle checkpoints or apoptosis, disallowing further studies of such cells. Laser dissection is restricted to a desired cell cycle phase (breaks are usually induced during metaphase), which may be beneficial if checkpoint activiation or apoptosis are cell-cycle stage dependent. In select experimental systems such as grasshopper spermatocytes, individual chromosomes can be manipulated using microdissection tips, and this could serve as an ideal test of holocentricity (Paliulis and Nicklas 2004). In principle, the ends of mitotic metaphase chromosomes should move freely in monocentric chromsomes, whereas they should be resistant to such physical stimulus in holocentric chromosomes (Doan and Paliulis 2009) (Fig. 1d).

A more precise method to identify holocentric chromosomes is is to visualize kinetochore proteins by immunofluorescence microscopy. Holocentric chromosomes will have kinetochore proteins bound along most if not the entire length of a metaphase chromosome, whereas 
A

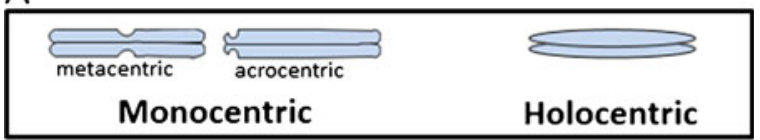

B

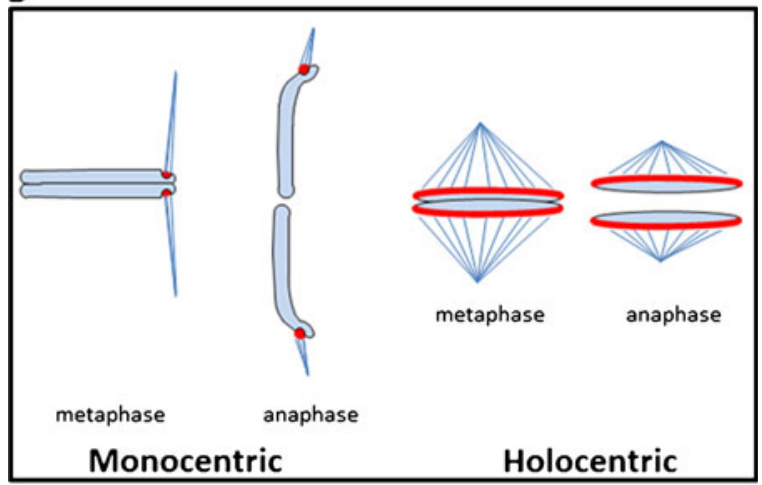

C

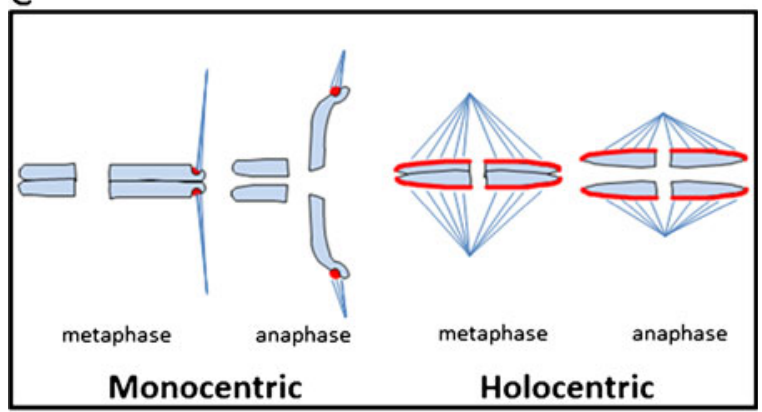

D

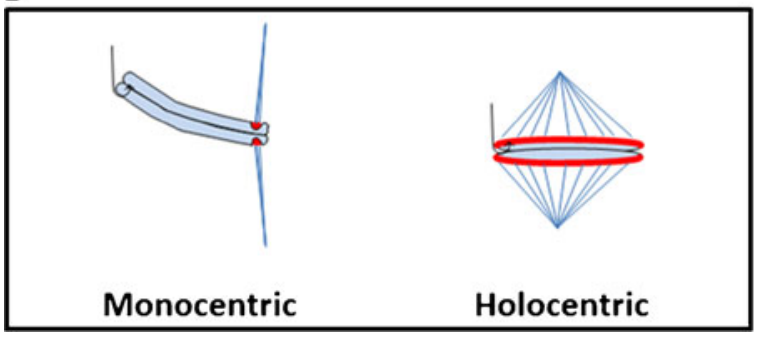

monocentric chromosomes will have a single discrete focus of localization. Kinetochore proteins such as the centromere-specific histone variant cenH3 (CENP-A in human), or members of the NDC80 microtubule-binding complex can be found from sequence analysis of most eukaryote genomes, even though many kinetochore proteins evolve too quickly for their orthologs to be detected by protein sequence similarity (Talbert et al. 2004, Meraldi et al. 2006). As sequencing becomes cheaper, kinetochore proteins will be identified from more
Fig. 1 How to diagnose holocentricity. a Monocentric chromosomes have a primary constriction. In metacentric chromosomes, the primary constriction is approximately equidistant from both chromosomal ends, whereas the primary constriction on acrocentric chromosomes is close to one of the ends. In contrast, holocentric chromosomes lack a primary constriction. b During anaphase, monocentric chromosome are pulled by spindle microtubules from a single point where the kinetochore is assembled. In holocentric chromosomes, the kinetochores are assembled along the length of the chromosome, and during anaphase, the two sister chromatids maintain their parallel relationship. c Upon chromosome fragmention, only two fragments of a monocentric chromosome will retain kinetochore function and segregate to the spindle poles. In holocentric chromosomes, all fragments migrate to the poles. d Micromanipulation of monocentric chromosome ends during metaphase results in the movement of just the chromosome end. In contrast, in holocentric chromosomes, where spindle microtubules display pulling forces over the length chromosome, the entire chromosome will be perturbed

putative holocentric organisms, and this approach is likely to become more widespread. Once a reference genome is available for a given organism, chromatin immunoprecipitation followed by sequencing (ChIPseq) can reveal whether kinetochore proteins are bound to a single centromere or to multiple locations on each chromosome. This method has recently been pioneered for holocentric organisms in C. elegans (Gassmann et al. 2012). As it is independent of cytology, ChIP-seq will be an especially useful method in the many organisms whose chromosomes are too small for reliable cytogenetic assays (many deeply diverged single-celled eukaryotes fall into this category).

\section{Broad phylogenetic distribution of holocentric chromosomes}

Holocentric chromosomes have radically different patterns of kinetochore protein deposition compared to monocentric chromosomes and require substantial changes in chromosome behavior to ensure accurate meiosis. Given these facts, it is interesting to ask how often this unusual chromosome structure has arisen during eukaryotic evolution. Most holocentric organisms were identified using cytology before molecular methods became available, and only a small subset of these studies used the more stringent method of chromosome fragmentation. As mentioned above, cytogenetic identification of holocentricity is much easier for large chromosomes. In all, 768 species have been reported to have holocentric chromosomes (including 
472 insects, 228 plants, 50 arachnids, and 18 nematodes) (Supplementary Table 1). There are several cases in which reports of holocentric chromosomes have been later corrected by more careful cytological studies, such as the moss Pleurozium schreberi and the marine alga Spirogyra (Godward 1954; Vaarama 1954; Mughal and Godward 1973; Kuta et al. 1998, 2000). To reduce the possibility of false positives, we focus on well-substantiated cases in this review, especially those in clades with more than one holocentric species. As molecular methods are applied to eukaryotes with small chromosomes, many additional holocentric clades may be discovered. We cannot be sure whether the last common ancestor of all eukaryotes had mono- or holocentric chromosomes. However, we infer by parsimony that monocentricity was the ancestral state. The sporadic and phylogenetically widespread occurrence of holocentricity in the tree of life suggests that the habit evolved from monocentric chromosomes at least 13 independent times (Fig. 2). We summarize the evolution of holocentric chromosomes in plants and animals in separate sections below.

\section{Holocentric chromosomes evolved at least four independent times in plants}

All known holocentric plant species belong to the flowering plants (phylum Angiosperma) and include both monocots and eudicots (Fig. 2). The holocentric monocots predominantly belong to the rush grasses (family Juncaceae) and sedges (family Cyperaceae) (Luceño et al. 1998; Kuta et al. 2004). These include the snowy woodrush Luzula nivea (Juncaceae), the most well-studied holocentric plant. Not all genera in Cyperaceae and Juncaceae are holocentric. For example, localized centromeres were reported in the aquatic

Fig. 2 Holocentricity has evolved at least 13 times in animals and plants. A depiction of the phylogenetic relationship of species with reported holocentric chromosomes and their close relatives with monocentric chromosomes is shown (Bremer 2002; Grimaldi and Engel 2005; Mitreva et al. 2005; De Ley 2006; Bradley et al. 2009; Regier et al. 2010; Maddison). The most parsimonious estimates are that holocentricity has evolved 13 times (red circles) and monocentricity has evolved from a holocentric ancestor two times (black circles). The clades that consist of species with holocentric chromosomes are depicted by red names, whereas clades that consist of species with monocentric chromosomes are depicted by black names. The green names represent clades for which no karyotype data exists

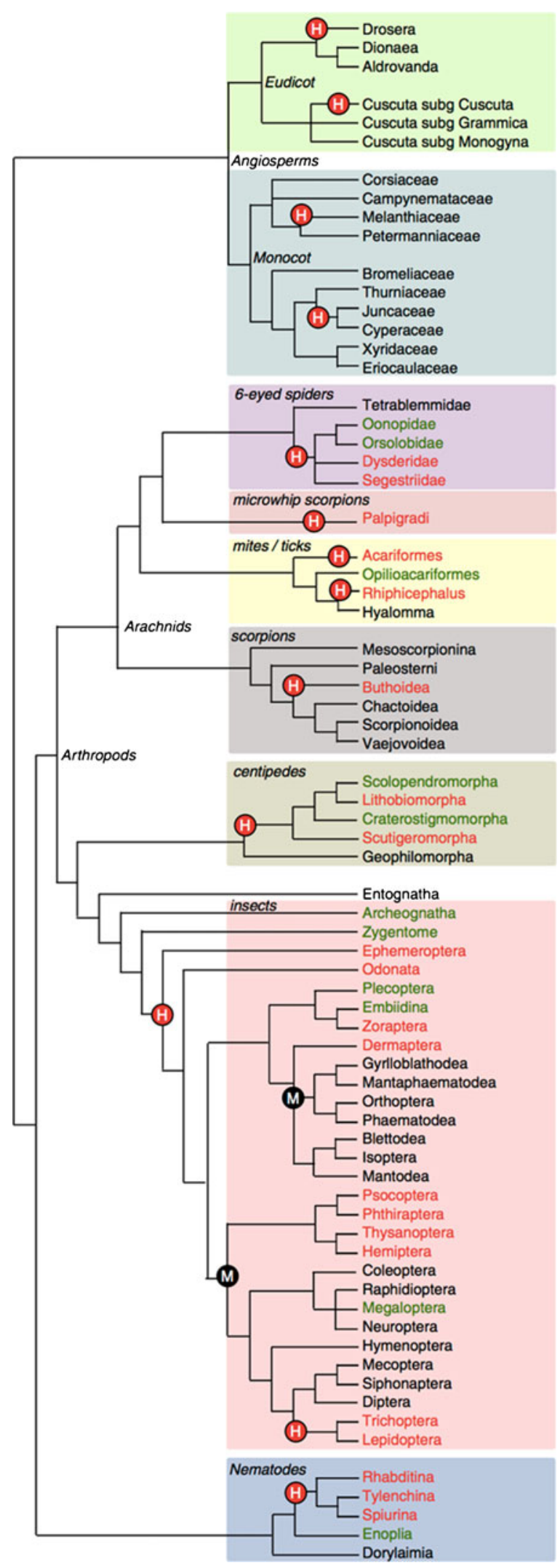


grass genus Scirpus (Nijalingappa 1974). Flowering perennial herbs from the genus Chionographis (family Melanthiaceae) (Tanaka and Tanaka 1977) also contain holocentric chromosomes.

Holocentric eudicots are limited to two genera: Drosera or sundews (family Droseraceae) and Cuscuta or dodders (family Convulvulaceae) (oddly, both are parasitic in nature). Cuscuta contains three subgenera, Cuscuta subgenus Cuscuta, Cuscuta subgenus Grammica, and Cuscuta subgenus Monogyna. Only the subgenus Cuscuta and one species in the subgenus Grammica are holocentric, offering an attractive opportunity for comparative genomics (Pazy and Plitmann 1994; Sheikh and Kondo 1995; Guerra et al. 2010).

\section{Holocentric chromosomes are likely to have evolved at least nine independent times in animals}

In the Animal Kingdom, holocentric chromosomes have been found in two phyla: Nematoda and Arthropoda. We estimate that holocentric chromosomes arose once in the Nematoda and eight times in Arthropoda.

The most well-known group of holocentric species can be found in the Secernentea class of the nematodes, which includes C. elegans. Other nematodes are usually described as holocentric because of their phylogenetic relationship to $C$. elegans rather than because of karyotypic evidence. The parasitic roundworms Trichinella and Trichuris (order Trichurida) (Mutafova et al. 1982; Spakulová et al. 1994) have been described as having monocentric chromosomes, whereas conflicting experimental data is available for Onchocerca volvulus, the causative agent of river blindness (Procunier and Hirai 1986; Hirai et al. 1987; Post 2005).

Holocentric chromosomes are found in many clades within the phylum Arthropoda (invertebrate animals with an exoskeleton). Notably, true bugs (Hemiptera) include the first well-characterized holocentric chromosomes. Diffuse binding of spindle microtubules along chromosomes was noted as early as 1935, and mitotic segregation of chromosome fragments was used to confirm holocentricity in scale insects soon afterward (Schrader 1935; Hughes-Schrader and Ris 1941; Hughes-Schrader and Schrader 1961). We have estimated a pattern for how the distribution of holocentric arthropods could have arisen from a monocentric ancestor, inferring by parsimony that the ancestor of all arthropods was monocentric (Fig. 2).

Holocentricity in the class Insecta (insects) is relatively common, being found in mayflies (order Ephemeroptera), dragonflies (order Odonata), angel insects (order Zoraptera), earwigs (order Dermaptera), caddisflies (order Trichoptera), moths and butterflies (order Lepidoptera), and the superorder Paraneoptera (encompassing lice, thrips, and true bugs). Large clades of monocentric insects are nested between these orders (it should be noted that insect phylogenetic relationships are still debated) (Grimaldi and Engel 2005; Regier et al. 2010). Therefore, we propose that the ancestor of most insect orders was holocentric, and that monocentricity returned twice during evolution of modern insects (Fig. 2). A second instance of holocentric chromosome evolution occurred during the divergence of Trichoptera and Lepidoptera from a monocentric ancestor. An isolated report of a monocentric hemipteran insect may represent a further reversion to the ancestral monocentric habit (Desai 1969; Desai and Deshpande 1969).

In contrast to Insecta, the class Arachnida (scorpions, spiders, mites and ticks) has few families or subfamilies with holocentric chromosomes. Holocentric arachnids include some spiders (order Araneae), microwhip scorpions (order Palpigradi), isolated mites and ticks (genuses Prostigmata and Radiicephalidae), and primitive scorpions (order Scorpiones). Holocentricity is also found in centipedes (class Chilopoda, closely related to arachnids). Karyotypic studies of mites and ticks suggest that many species may be monocentric, so we assume that holocentric chromosomes evolved twice in this order (Oliver 1972, 1977; Oliver et al. 1974). It is reasonable to assume that holocentric chromosomes arose at least six independent times during arthropod evolution and at least nine times overall in animals (Fig. 2).

\section{Holocentric chromosomes face a kinetochore geometry problem in meiosis}

The aim of meiosis is to reduce the chromosome number so haploid gametes are produced from a diploid parent cell. Reduction of chromosome number in meiosis happens because a single round of DNA replication is followed by two rounds of cell division. Correct 
chromosome segregation in meiosis requires changes in kinetochore geometry and differences in release of sister chromatid cohesion relative to mitosis. Holocentric chromosomes create unique problems during meiosis that organisms with monocentric chromosomes do not face. We review several diverse mechanisms that have arisen in holocentric organisms to allow correct distribution of chromosomes during meiosis.

The way a chromosome divides is based on its geometry. In mitosis, both monocentric and holocentric chromosomes have kinetochores whose spindlemicrotubule capture surfaces face in opposite directions, so sister chromatids are separated at anaphase (Paliulis and Nicklas 2004; John 1990). Although mitosis in holocentric chromosomes is straightforward, there is potential for major problems in meiosis. In prophase I, recombination and sister chromatid cohesion link homologous chromosomes together as a bivalent (Fig. 3a). Bivalents with a single chiasma

\section{A}

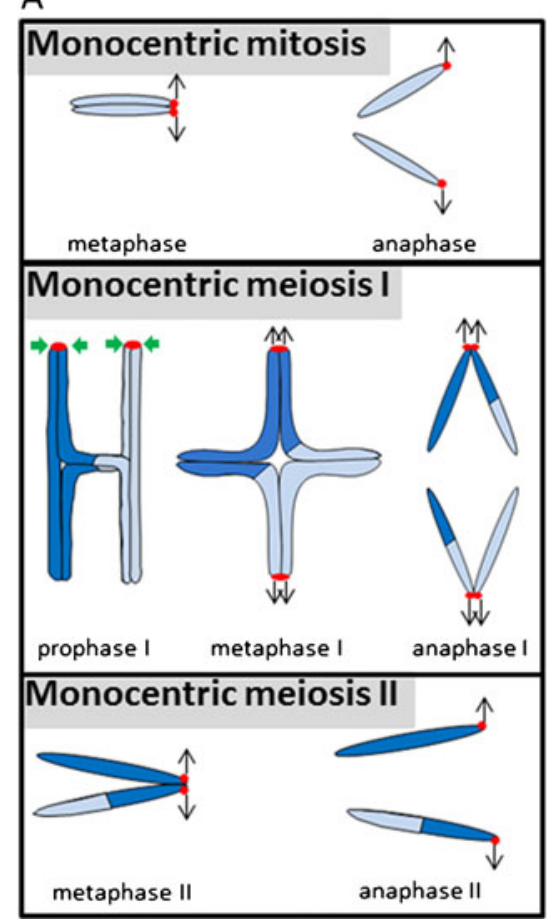

Fig. 3 Mitosis and meiosis with monocentric and holocentric chromosomes. a In mitosis, sister kinetochores of monocentric chromosomes face opposite spindle poles. This leads to separation of sister chromatids in anaphase of mitosis. In meiosis I, sister kinetochores are fused and face in the same direction. This leads to homologous-chromosome separation in anaphase I. In meiosis II, the sister kinetochores face in opposite directions in metaphase, and sister chromatids separate in anaphase II. b In (recombination site) are cruciform (Fig. 3a). In monocentric chromosomes, sister kinetochores fuse and face in the same direction in meiosis I. In anaphase I, cohesion between sister-chromatid arms is released while centromeric cohesion is protected, so the sister chromatids remain together and homologues are separated. In meiosis II, sister kinetochores face opposite spindle poles, so sister chromatids separate in anaphase II when centromeric cohesion is released (Paliulis and Nicklas 2005; John 1990). Holocentric chromosomes can theoretically attach to the meiosis I spindle at many positions along their length. Therefore, if a holocentric bivalent has no modification to its chromosome structure or kinetochore positioning, its microtubule capture surfaces will face in all directions (Fig. 3b). Depending on how cohesion is released, chromosomes could segregate randomly or not at all. Obviously, holocentric organisms require special adaptations to allow correct segregation of one chromatid to each gamete.

B

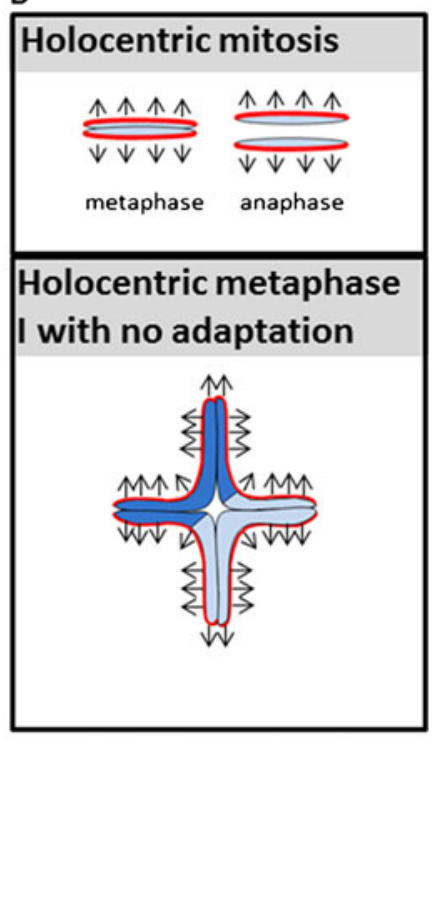

mitosis, kinetochores are distributed along the length of the holocentric chromosome arm, so chromosomes connect to the spindle all along their entire length. In anaphase, because the spindle-attachment sites face in opposite directions, sister chromatids separate from one another. In meiosis I, if there is no alteration of chromosome structure or attachment surface position, attachment sites can face in all directions, leading to problems in chromosome segregation 


\section{Holocentric meiosis in Caenorhabditis elegans}

The nematode $C$. elegans is the holocentric organism in which meiosis has been best studied. C. elegans bivalents tend to have a single chiasma placed closer to one end of the chromosome than the other (the end is chosen randomly). Therefore, they are cruciform in late prophase I and outwardly resemble monocentric chromosomes at the same stage (Monen et al. 2005;
Albertson and Thomson 1993) (Fig. 4a). Holocentric chromosomes in mitosis do not have a single centromere to act as a site for maintenance of sister chromatid cohesion. In C. elegans, cohesion is maintained distal to the chiasma, meaning that this structure has an important role in ensuring that homologues separate in anaphase I, but sister chromatids stay together until anaphase II. Before nuclear envelope breakdown of meiosis I, bivalents condense very tightly, so the
A

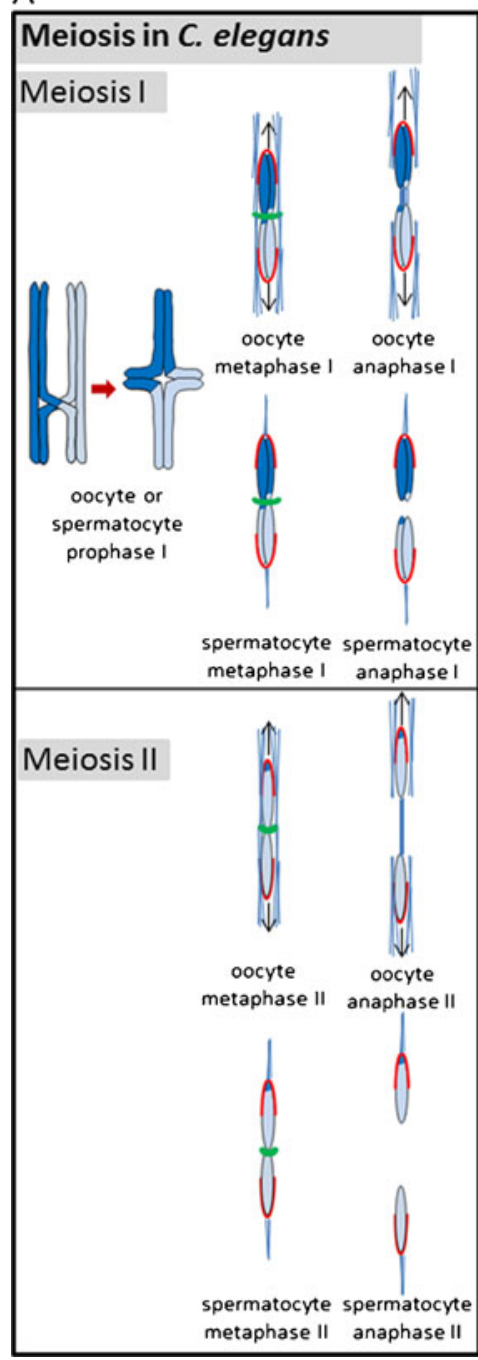

\section{$B$}

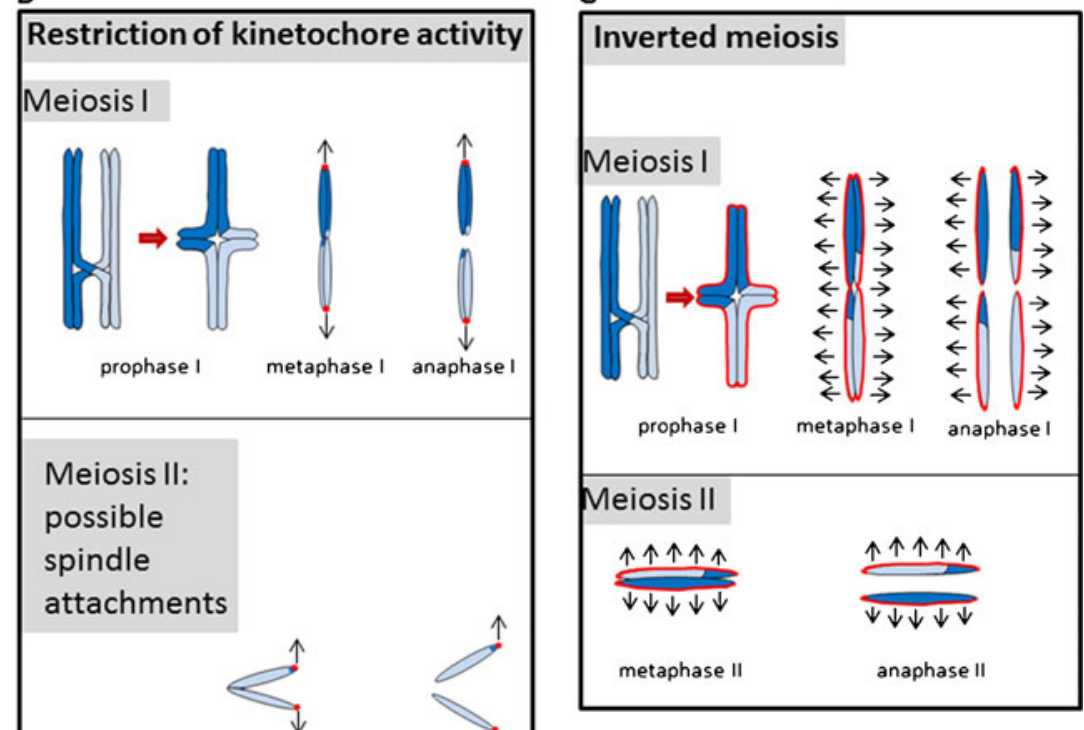

Fig. 4 Solutions to the problem of holocentric chromosomes in meiosis. a During meiosis in the nematode C. elegans in both the oocyte and spermatocyte the kinetochore forms a cupshaped structure in meiosis I. In oocytes, the spindles form a sheet around the bivalents, whereas in spermatocytes the spindle binding is restricted to the ends of the bivalents. In meiosis II, the sister chromatids separate similarly as in meiosis I. b In some insects, holocentric chromosomes in mitosis behave as monocentric chromosomes in meiosis. Kinetochore activity is limited to one end of the chromosome (randomly chosen). $\mathbf{c}$ In inverted meiosis, sister chromatids separate in the first meiotic division. It is speculated that this separation happens because chiasmata are terminalized in prophase of meiosis I, such that chromosomes are arranged in metaphase I with sister chromatids facing opposite poles. In anaphase I, all chromatids separate. Then, homologous chromatids re-pair prior to meiosis II 
short arms of the cruciform are no longer visible and the bivalent takes on a capsule shape (Schvarzstein et al. 2010). Each end of the bivalent (Fig. 4a) faces a spindle pole and moves toward that pole in anaphase. The kinetochore proteins CENP-C, KNL-1, BUB-1, HIM-10, NDC-80, Nuf2, and MIS-12 form a cup around each end of the bivalent (Monen et al. 2005). Intriguingly, this structure is independent of the centromere-specific histone HCP-3 (the ortholog of cenH3/CENP-A/Cid). In oocytes, lateral interactions between the bivalent and spindle microtubules, which form a sheath around each bivalent, facilitate congression to the metaphase plate (Monen et al. 2005). The chromokinesin KLP 19, which forms a ring around the equator of the bivalent, exerts a polar ejection force that aids congression (Wignall and Villeneuve 2009).

Because both oocyte and spermatocyte meiosis can be visualized in $C$. elegans, interesting mechanistic differences between the two have been observed. In spermatocytes, spindle-attachment is restricted to each end of a bivalent, as microtubules are embedded in focused areas on each chromosome (Albertson and Thomson 1993; Shakes et al. 2009; Wignall and Villeneuve 2009). Despite this limited attachment, kinetochore proteins appear to form a cup around each entire half-bivalent as they do in oocytes (Shakes et al. 2009; Wignall and Villeneuve 2009). In spermatocytes, each chromosome end acts functionally as a kinetochore, binding to spindle microtubules and allowing congression to the metaphase plate (Shakes et al. 2009). Anaphase chromosome separation occurs because cohesion distal to the chiasma is released (Fig. 4a). In oocytes, homologue segregation appears to be driven by growth of microtubules between separating homologues (Dumont et al. 2010). In spermatocytes, however, homologues move toward their associated spindle pole along microtubules attached to the "kinetochore" at each end of the bivalent (Shakes et al. 2009).

\section{Restriction of kinetochore activity in the true bugs (Hemiptera)}

Meiosis in the true bugs (Hemiptera: Heteroptera) resembles that of $C$. elegans spermatocytes, in that kinetochore activity is restricted to a small region of a chromosome (notably, meiosis in Hemiptera has been mainly studied in spermatocytes) (Fig. 4b). Electron microscopy shows that the mitotic holocentric kinetochore in the milkweed bug Oncopeltus fasciatus has a layered appearance with visible kinetochore plates, while in meiosis, the areas of kinetic activity are more diffuse (Comings and Okada 1972). After crossover, bivalents condense very strongly and terminalize their chiasmata so they take on a capsule shape similar to that of C. elegans chromosomes (Wolfe and John 1965). Kinetochore activity in meiosis is restricted to the ends of the capsule-shaped bivalent, and chromosome cohesion is lost in a two-step pattern. This ensures that homologous chromosomes separate in anaphase I and sister chromatids separate in anaphase II, leading to the formation of haploid gametes. Mechanisms for forming the temporary kinetochore and for differential retention of cohesion between anaphase I and II are not well understood. It will be interesting to determine if bugs use a similar mechanism to C. elegans for selecting which end of the chromosome faces the spindle pole and has kinetochore activity. One interesting finding is that the chromosome end chosen to act as a temporary kinetochore can switch between the two meiotic divisions, as seen in Triatoma infestans (Heteroptera) (Pérez et al. 1997). Amazingly, meiosis II in T. infestans can feature sister chromatids with kinetochores at opposite ends (Pérez et al. 2000).

\section{Inverted meiosis}

An alternative solution to the problem of holocentric chromosomes in meiosis is to invert the meiotic divisions, so that sister chromatids separate in meiosis I and homologues separate in meiosis II (Fig. 4c). Inverted meiosis appears in both animals and plants, including a suborder of true bugs (Homoptera), some dragonflies and damselflies, some arachnids, and woodrushes of the genus Luzula (Viera et al. 2009). It is best studied in the true bugs (Homoptera), where most species have at least one sex with inverted meiosis (John 1990). In meiotic prophase of these species, chromosomes recombine, and chiasmata are terminalized as in the Heteroptera (Hughes-Schrader 1944; John and Claridge 1974; John 1990) (Fig. 4c). In inverted meiosis, chromosomes align differently than in cases of restricted kinetochore activity. Sister chromatids face opposite poles and separate from one another in anaphase I (Fig. 4c). All cohesion appears to be lost between chromatids by telophase I (Hughes-Schrader 1944; John 1990). Homologous chromatids re-pair prior to the second meiotic division and separate from one another in anaphase II. The 
molecular mechanisms underlying inverted meiosis have not been studied.

Restricted kinetochore activity and inverted meiosis can coexist in the same cell. In the Heteroptera, autosomes restrict kinetic activity (Comings and Okada 1972; Wolfe and John 1965), while sex chromosomes undergo inverted meiosis (Schrader 1935; Pérez et al. 2000; Viera et al. 2009). The sex chromosomes of Heteroptera differ from autosomes of Homoptera. Either they lack a pairing partner (in $\mathrm{XX}-\mathrm{X} 0$ sex determination), or the $\mathrm{X}$ and $\mathrm{Y}$ chromosomes do not recombine. Thus, in meiosis I, the sex chromosomes align on the spindle and behave like holocentric chromosomes in mitosis, separating sister chromatids (Schrader 1935; Pérez et al. 2000; Viera et al. 2009). In meiosis II in organisms with XX-X0 sex determination, the lone $\mathrm{X}$ moves to one spindle pole in anaphase II (Schrader 1935). In organisms with XX-XY sex determination, sister chromatids of the $\mathrm{X}$ and $\mathrm{Y}$ chromosomes separate in anaphase I. In meiosis II, the $\mathrm{X}$ and $\mathrm{Y}$ chromatids re-pair, align on the metaphase plate, then separate in anaphase II (Pérez et al. 2000; Viera et al. 2009). Again, little is known about proteins that regulate these behaviors.

\section{Other meiotic adaptations in holocentric organisms}

In some Homoptera, formation of gametes in males does not require meiosis at all. In species with haploid males and diploid females, males form sperm via typical mitotic divisions and females have inverted meiosis (Hughes-Schrader and Tremblay 1966). Other Homoptera (e.g., Phenacoccus) have diploid males who generate haploid sperm starting with a mitotic division. To achieve this, one haploid set of chromosomes is inactivated and maintained as heterochromatin (the haploid chromosome sets are separately marked by imprinting). During meiosis II, the active chromosome set segregates to one end of the cell and is incorporated into a sperm, while the inactive chromosome set is sequestered in a separate nucleus and eventually ejected (Hughes-Schrader 1935).

Meiosis in some holocentric organisms remains poorly characterized. In addition, it remains unclear why very different meiotic adaptations exist and why the closely related clades (e.g., the two suborders of Hemiptera) utilize such different mechanisms. Molecular characterization of meiosis in holocentric organisms is likely to illuminate these questions.

\section{Genomic tools to study genomes of holocentric species}

For most species with holocentric chromosomes, the DNA sequence underlying the kinetochore is unknown. Recently, the chromosomal localization of the centromere-specific histone cenH3 was determined in the nematode $C$. elegans by ChIP-chip analysis (Gassmann et al. 2012). It was found that $\sim 50 \%$ of the genome can be associated with cenH3, showing that particular DNA sequences are unlikely to control cenH3 incorporation (furthermore, up to $90 \%$ of the nucleosomes in these centromeric regions may contain conventional H3). Importantly, the distribution of cenH3-containing regions was inversely correlated with genes transcribed in the germline and early embryo when the pattern of cenH3 incorporation is established (Gassmann et al. 2012). This suggests that transcription excludes cenH3 incorporation.

The chromosomes of most animal and plant species are monocentric, and the centromeres of these species are usually characterized by high-copy tandem repeat arrays (Henikoff et al. 2001; Melters et al., in preparation). The genome of $C$. elegans contains few tandem repeats (Hillier et al. 2007), but this is not the case for all genomes of species with holocentric chromosomes (Table 1), e.g., in the snowy woodrush $L$. nivea and its close relative $L$. elegans (Nagaki et al. 2005; Heckmann et al. 2011). In contrast to $C$. elegans, a high-copy 178-bp tandem repeat was found in the genome of $L$. nivea (Haizel et al. 2005). This repeat formed at least five distinct arrays per chromosome when studied by FISH. Whether cenH3 is preferentially localized to these large tandem repeat arrays remains to be determined.

With advances in genome sequencing technology, the genomes of dozens of holocentric species are available. Bioinformatic tools can find and analyze high-copy tandem repeats from shotgun genome sequences (Alkan et al. 2011; Melters et al., in preparation). One recent study surveyed tandem repeats in 282 animal and plant species, including 32 holocentric species (11 arthropods and 21 nematodes) (Melters et al., in preparation). The genomic abundance of tandem repeats in these 32 species differs greatly. The majority has only low-copy tandem repeats similar to $C$. 
Table 1 List of species with holocentric chromosomes and literature reports of tandem repeats and the chromosomal localization of the tandem repeat if known

\begin{tabular}{|c|c|c|c|c|}
\hline Species & Common name & Length (bp) & Localization & References \\
\hline \multicolumn{5}{|l|}{ Juncaceae; Monocots } \\
\hline Luzula flaccida & Pale woodrush & 127 & Interspersed & Collet (1984) \\
\hline Luzula flaccida & Pale woodrush & 190 & N/A & Collet (1984) \\
\hline Luzula flaccida & Pale woodrush & 184 & N/A & Collet (1984) \\
\hline Luzula nivea & Snowy woodrush & 178 & Interspersed & Haizel et al. (2005) \\
\hline \multicolumn{5}{|l|}{ Lepidoptera; Insecta } \\
\hline Mamestra brassicae & Cabbage moth & 234 & Subtelomeric & Mandrioli et al. (2003) \\
\hline Spodoptera frugiperda & Fall armyworm & 189 & N/A & Lu et al. (1994) \\
\hline \multicolumn{5}{|l|}{ Hemiptera; Insecta } \\
\hline Myzus persicae & Peach potato aphid & 169 & Subtelomeric & Spence et al. (1998) \\
\hline Myzus persicae & Peach potato aphid & 189 & Subtelomeric & Mandrioli et al. (1999) \\
\hline \multicolumn{5}{|l|}{ Ixodidae; Arachnida } \\
\hline Rhipicephalus microplus & Southern cattle tick & 149 & Subtelomeric & Hill et al. (2009) \\
\hline Rhicicephalus microplus & Southern cattle tick & 178 & Subtelomeric & Hill et al. (2009) \\
\hline Rhicicephalus microplus & Southern cattle tick & 177 & Subtelomeric & Hill et al. (2009) \\
\hline Rhicicephalus microplus & Southern cattle tick & 216 & Subtelomeric & Hill et al. (2009) \\
\hline \multicolumn{5}{|l|}{ Ascarididae; Nematoda } \\
\hline Ascaris suum & Pig roundworm & 123 & Subtelomeric $^{\mathrm{a}}$ & $\begin{array}{l}\text { Niedermaier and Moritz (2000); } \\
\text { Streeck et al. (1982) }\end{array}$ \\
\hline Ascaris lumbricoides & Roundworm & 121 & N/A & Müller et al. (1982) \\
\hline Parascaris univalens & Roundworm & 5 & Subtelomeric $^{\mathrm{a}}$ & $\begin{array}{l}\text { Niedermaier and Moritz (2000); } \\
\text { Teschke et al. (1991) }\end{array}$ \\
\hline Parascaris univalens & Roundworm & 10 & Subtelomeric $^{\mathrm{a}}$ & Niedermaier and Moritz (2000) \\
\hline \multicolumn{5}{|l|}{ Rhabditida; Nematoda } \\
\hline Steinernema glaseri & Roundworm & 174 & N/A & Grenier et al. (1996) \\
\hline Heterorhabditis bacteriophora & Roundworm & 168 & N/A & Grenier et al. (1996) \\
\hline Heterorhabditis indicus & Roundworm & 174 & $\mathrm{~N} / \mathrm{A}$ & Abadon et al. (1998) \\
\hline Panagrellus redivivus & Roundworm & 155 & $\mathrm{~N} / \mathrm{A}$ & de Chastonay et al. (1990) \\
\hline Panagrellus redivivus & Roundworm & 167 & N/A & de Chastonay et al. (1990) \\
\hline Ostertagia circumcincta & Red stomach worm & 218 & N/A & Callaghan and Beh (1996) \\
\hline \multicolumn{5}{|l|}{ Aphelenchida; Nematoda } \\
\hline Bursaphelenchus xylophilus & Pine wood nematode & 160 & N/A & Tarès et al. (1993) \\
\hline \multicolumn{5}{|l|}{ Tylenchida; Nematoda } \\
\hline Meloidogyne hapla & Root-knot nematode & 169 & N/A & Piotte et al. (1994) \\
\hline Meloidogyne incognita & Root-knot nematode & 295 & N/A & Piotte et al. (1994) \\
\hline Meloidogyne chitwoodi & Root-knot nematode & 180 & N/A & Castagnone-Sereno et al. (1998) \\
\hline Meloidogyne arenaria & Root-knot nematode & 172 & N/A & $\begin{array}{l}\text { Castagnone-Sereno et al. (2000); } \\
\text { Mestrović et al. (2005) }\end{array}$ \\
\hline
\end{tabular}

${ }^{\text {a }}$ Species with chromatin diminution (Müller et al. 1996)

elegans, but some holocentric species have high-copy tandem repeats with an overall genomic abundance comparable to that of the monocentric Arabidopsis thaliana and human genomes. These may represent cases like $L$. nivea in which tandem repeats have spread to several locations along each chromosome.

High-copy tandem repeats have also been studied experimentally in holocentric organisms (Table 1). 
These tandem repeats were often localized to subtelomeric regions (Spence et al. 1998; Malik and Henikoff 2009; Mandrioli et al. 2003; Hill et al. 2009). With the restricted kinetochore activity in meiosis observed in some holocentric species, it is tempting to ask if tandem repeat arrays have a role in specifying centromere activity in meiosis.

\section{Evolutionary implications of holocentric chromosomes}

In theory, holocentric chromosomes encourage rapid karyotype evolution. Fission of a holocentric chromosome should create two fragments that both retain centromere activity. Similarly, fusion of holocentric chromosomes would not create the problems faced by a dicentric chromosome in a monocentric organism. These predictions are based on mitotic chromosome segregation, and some types of meiotic adaptation (e.g., kinetochore restriction) may be fatally affected by chromosome fission. In general, holocentric clades do not show the predicted increase in karyotypic diversity (Panzera et al. 1996; Gokhman and Kuznetsova 2006). In contrast, sedges (genus Carex), scale insects (genus Apiomorpha), and scorpions from the family Buthidae have extremely labile karyotypes (Cook 2000; Hipp 2007; Schneider et al. 2009). Carex has inverted meiosis, and Buthidae have achiasmate meiosis (Davies 1956; Schneider et al. 2009). These features may have allowed karyotypes to change without compromising holocentric meiosis (Schneider et al. 2009).

The holocentric chromosome characteristic is also likely to affect the evolution of centromere DNA sequences and of the kinetochore proteins that bind to them. Despite the essential function of centromeres in chromosome segregation, centromere DNAs and many kinetochore proteins evolve very rapidly (Talbert et al. 2004, Meraldi et al. 2006). Henikoff et al. (2001) and Malik and Henikoff (2009) have proposed a female meiotic drive hypothesis to explain this paradox. Asymmetric meiosis in females generates only one functional egg cell from four gametes, and centromere DNA sequence polymorphisms that encourage segregation into the surviving egg cell will have a huge selective advantage. Correspondingly, kinetochore proteins such as cenH3 would coevolve to equalize binding between all centromeres in a population, ensuring that unequal centromere DNA/kinetochore protein interactions do not cause chromosome segregation errors. Tandem repeats are likely to facilitate rapid evolution of centromere DNA in monocentric chromosomes. A sequence polymorphism that shows preferential segregation could spread from one chromosome to another by gene conversion because tandem repeats on all chromosomes have similar sequences.

Genomic evidence suggests that many holocentric chromosomes lack tandem repeats and have cenH3 binding sites distributed over a wide variety of unique sequences (C. elegans is the exemplar of such organisms) (Gassmann et al. 2012; Melters et al., in preparation). If cenH3 binds to such a diverse range of sites, it may be much more difficult for holocentric chromosomes to acquire DNA sequence changes that favor segregation into the surviving egg cell during female meiosis. Changes in centromere DNA evolution might relax the pressure on cenH3 to evolve rapidly, a prediction that should be testable in holocentric clades. Interesting, Caenorhabditis cenH3 continues to show signs of positive selection despite the fact that it binds to diverse DNA sequences in holocentric chromosomes (Zedek and Bureš 2012).

Another factor that is likely to influence centromere DNA evolution is the mechanism of kinetochore assembly during meiosis in holocentric organisms. We do not know if particular DNA sequences are important for assembling the cup-shaped kinetochore protein structures seen in C. elegans meiosis, and chromosome segregation is cenH3 independent in meiosis (Monen et al. 2005). Similarly, inverted meiosis seems to feature spindle attachment sites that are spread along the length of meiotic chromosomes and may assemble on unique sequences in many holocentric organisms. Only in holocentric organisms such as L. nivea, which has tandem repeats underlying cenH3 binding sites, is it possible for centromere DNA to evolve rapidly in the same manner as it does in monocentric chromosomes (Haizel et al. 2005). Luzula has inverted meiosis with distributed kinetochore activity. Centromere repeat evolution may well be different in inverted meiosis organisms when compared with holocentric organisms that restrict kinetochore activity to particular chromosome regions (especially if these regions contain high-copy tandem repeats).

\section{Final remarks}

How do holocentric chromosomes inform our general understanding of the chromosome segregation machinery? 
Given the extreme meiotic adaptations necessary for organisms to adopt holocentric chromosomes, it is surprising and fascinating that distributed kinetochores have arisen so many times during eukaryotic evolution. It is likely that kinetochore location is controlled epigenetically in almost all eukaryotes (Stimpson and Sullivan 2010). Convergent evolution of holocentric chromosomes in extremely disparate eukaryotes suggests that cenH3 recruitment and maintenance can be altered relatively easily to greatly alter the placement of kinetochore proteins on mitotic chromosomes. Recent results from A. thaliana suggest that meiotic kinetochores have a unique assembly pathway, possibly because sister kinetochores must be mono-oriented towards the same side of the spindle (Ravi et al. 2011). Meiosis in holocentric organisms has several different solutions to the problem of kinetochore geometry, further suggesting that centromere assembly in meiosis can be altered without affecting the nature of mitotic cenH3 recruitment.

A flurry of recent papers describing cenH3 from deeply diverged eukaryotes shows how inexpensive genome sequencing is changing our ability to address questions in comparative cell biology (Maruyama et al. 2008; Dawson et al. 2007; Dubin et al. 2010; Brooks et al. 2011). It will be very interesting to ask whether holocentric chromosomes are seen in any single celled eukaryotes whose genomes are too small for classical cytology. Similarly, it is now much easier to generate molecular reagents and to inactivate genes in non-model organisms (for example, with TALE nucleases) (Bogdanove and Voytas 2011). These tools should allow investigators to make great inroads in our understanding of centromere assembly and meiotic adaptations in organisms with holocentric chromosomes.

Acknowledgments We are indebted to P. Ward, P. Gullan, and P. Cranston for their advice on insect phylogeny. D.M. was supported by training grant T32-GM08799 from NIH-NIGMS. Its contents are solely the responsibility of the authors and do not necessarily represent the official views of the NIGMS or NIH. S.C. is a Howard Hughes Medical Institute and Gordon and Betty Moore Foundation investigator.

\section{References}

Abadon M, Grenier E, Laumond C, Abad P (1998) A species-specific satellite DNA from the entomopathogenic nematode Heterorhabditis indicus. Genome 41 (2):148-153
Albertson DG, Thomson JN (1993) Segregation of holocentric chromosomes at meiosis in the nematode, Caenorhabditis elegans. Chromosom Res 1(1):15-26

Alkan C, Cardone MF, Catacchio CR, Antonacci F, O'Brien SJ, Ryder OA, Purgato S, Zoli M, Della Valle G, Eichler EE, Ventura M (2011) Genome-wide characterization of centromeric satellites from multiple mammalian genomes. Genome Res 21(1):137-145

Bogdanove AJ, Voytas DF (2011) TAL effectors: customizable proteins for DNA targeting. Science(New York, NY) 333 (6051):1843-1846

Bradley TJ, Briscoe AD, Brady SG, Contreras HL, Danforth BN, Dudley R, Grimaldi D, Harrison JF, Kaiser JA, Merlin C (2009) Episodes in insect evolution. Integr Comp Biol 49(5):590-606

Bremer K (2002) Gondwanan evolution of the grass alliance of families (Poales). Evol Int J Org Evol 56(7):1374-1387

Brooks CF, Francia ME, Gissot M, Croken MM, Kim K, Striepen B (2011) Toxoplasma gondii sequesters centromeres to a specific nuclear region throughout the cell cycle. Proc Natl Acad Sci USA 108(9):3767-3772

Callaghan MJ, Beh KJ (1996) A tandemly repetitive DNA sequence is present at diverse locations in the genome of Ostertagia circumcincta. Gene 174(2):273-279

Castagnone-Sereno P, Leroy H, Semblat JP, Leroy F, Abad P, Zijlstra C (1998) Unusual and strongly structured sequence variation in a complex satellite DNA family from the nematode Meloidogyne chitwoodi. J Mol Evol 46(2):225-233

Castagnone-Sereno P, Leroy F, Abad P (2000) Cloning and characterization of an extremely conserved satellite DNA family from the root-knot nematode Meloidogyne arenaria. Genome 43(2):346-353

Collet C (1984) Highly repeated DNA and holocentric chromosomes of the woodrush Luzula flaccida (Juncaceae). Can J Genet Cytol 26(3):288-295

Comings DE, Okada TA (1972) Holocentric chromosomes in Oncopeltus: kinetochore plates are present in mitosis but absent in meiosis. Chromosoma 37(2):177-192

Cook LG (2000) Extraordinary and extensive karyotypic variation: a 48-fold range in chromosome number in the gallinducing scale insect Apiomorpha (Hemiptera: Coccoidea: Eriococcidae). Genome 43(2):255-263

Davies EW (1956) Cytology, evolution and origin of the aneuploid series in the genus Carex. Hereditas 42:349-365

Dawson SC, Sagolla MS, Cande WZ (2007) The cenH3 histone variant defines centromeres in Giardia intestinalis. Chromosoma 116(2):175-184

de Chastonay Y, Müller F, Tobler H (1990) Two highly reiterated nucleotide sequences in the low $\mathrm{C}$-value genome of Panagrellus redivivus. Gene 93(2):199-204

De Ley P (2006) A quick tour of nematode diversity and the backbone of nematode phylogeny. WormBook:1-8

Dernburg AF (2001) Here, there, and everywhere: kinetochore function on holocentric chromosomes. J Cell Biol 153(6): F33-F38

Desai RN (1969) Monocentric nature of the chromosomes of Ranatra (heteroptera) verified by the induced fragmentation experiments. Cell Mol Life Sci 25(11):1170-1171

Desai RN, Deshpande SB (1969) Centromere nature of the chromosomes ofRanatra (Heteroptera). Cell Mol Life Sci 25(4):386-387 
Doan RN, Paliulis LV (2009) Micromanipulation reveals an $\mathrm{XO}-\mathrm{XX}$ sex determining system in the orb-weaving spider Neoscona arabesca (Walckenaer). Hereditas 146(4):180-182

Dubin M, Fuchs J, Gräf R, Schubert I, Nellen W (2010) Dynamics of a novel centromeric histone variant $\mathrm{CenH} 3$ reveals the evolutionary ancestral timing of centromere biogenesis. Nucleic Acids Res 38(21):7526-7537

Dumont J, Oegema K, Desai A (2010) A kinetochoreindependent mechanism drives anaphase chromosome separation during acentrosomal meiosis. Nat Cell Biol 12 (9):894-901

Fuková I, Traut W, Vítková M, Nguyen P, Kubícková S, Marec F (2007) Probing the W chromosome of the codling moth, Cydia pomonella, with sequences from microdissected sex chromatin. Chromosoma 116(2):135-145

Gassmann R, Rechtsteiner A, Yuen KW, Muroyama A, Egelhofer T, Gaydos L, Barron F, Maddox P, Essex A, Monen J, Ercan S, Lieb JD, Oegema K, Strome S, Desai A (2012) An inverse relationship to germline transcription defines centromeric chromatin in C. elegans. Nature 484:534 537

Godward MBE (1954) Irradiation of Spirogyra chromosomes. Heredity 8(2):293

Gokhman VE, Kuznetsova VG (2006) Comparative insect karyology: current state and applications. Entomol Rev 86 (3):352-368

Grenier E, Laumond C, Abad P (1996) Molecular characterization of two species-specific tandemly repeated DNAs from entomopathogenic nematodes Steinernema and Heterorhabditis (Nematoda: Rhabditida). Mol Biochem Parasitol 83(1):47-56

Grimaldi D, Engel MS (2005) Evolution of the insects. Cambridge University Press, Cambridge

Guerra M, Cabral G, Cuacos M, González-García M, GonzálezSánchez M, Vega J, Puertas MJ (2010) Neocentrics and holokinetics (holocentrics): chromosomes out of the centromeric rules. Cytogenet Genome Res 129(1-3):82-96

Haizel T, Lim YK, Leitch AR, Moore G (2005) Molecular analysis of holocentric centromeres of Luzula species. Cytogenet Genome Res 109(1-3):134-143

Heckmann S, Schroeder-Reiter E, Kumke K, Ma L, Nagaki K, Murata M, Wanner G, Houben A (2011) Holocentric chromosomes of Luzula elegans are characterized by a longitudinal centromere groove, chromosome bending, and a terminal nucleolus organizer region. Cytogenet Genome Res 134(3):220-228

Henikoff S, Ahmad K, Malik HS (2001) The centromere paradox: stable inheritance with rapidly evolving DNA. Science 293(5532):1098-1102

Hill CA, Guerrero FD, Van Zee JP, Geraci NS, Walling JG, Stuart JJ (2009) The position of repetitive DNA sequence in the southern cattle tick genome permits chromosome identification. Chrom Res 17(1):77-89

Hillier LW, Miller RD, Baird SE, Chinwalla A, Fulton LA, Koboldt DC, Waterston RH (2007) Comparison of $C$. elegans and C. briggsae genome sequences reveals extensive conservation of chromosome organization and synteny. PLos Biol 5(7):e167

Hipp AL (2007) Nonuniform processes of chromosome evolution in sedges (Carex: Cyperaceae). Evol Int J Org Evol 61 (9):2175-2194
Hirai H, Tada I, Takahashi H, Nwoke BE, Ufomadu GO (1987) Chromosomes of Onchocerca volvulus (Spirurida: Onchocercidae): a comparative study between Nigeria and Guatemala. J Helminthol 61(1):43-46

Hughes-Schrader S (1935) The chromosome cycle of Phenacoccus (Coccidae). Biol Bull 69(3):462-468

Hughes-Schrader S (1944) A primitive coccid chromosome cycle in Puto sp. Biol Bull 87(3):167-176

Hughes-Schrader S, Ris H (1941) The diffuse spindle attachment of coccids, verified by the mitotic behavior of induced chromosome fragments. J Exp Zool 87(3):429-456

Hughes-Schrader S, Schrader F (1961) The kinetochore of the Hemiptera. Chromosoma 12(1):327-350

Hughes-Schrader S, Tremblay E (1966) Gueriniella and the cytotaxonomy of iceryine coccids (Coccoidea: Margarodidae). Chromosoma 19(1):1-13

John B (1990a) Meiosis. Cambridge University Press, Cambridge

John B, Claridge MF (1974) Chromosome variation in British populations on Oncopsis (Hemiptera: Cicadellidae). Chromosoma 46(1):77-89

Kuta E, Przywara L, Hejmej J (1998) Karyotype variability in Pleurozium schreberi (Brid.) Mitt. Acta Biol Cracov Ser Bot 40:75-84

Kuta E, Przywara L, Ilnicki T (2000) Heterochromatin in Pleurozium schreberi (Brid.) Mitt. Acta Biol Cracov Ser Bot 42:55-59

Kuta E, Bohanec B, Dubas E, Vizintin L, Przywara L (2004) Chromosome and nuclear DNA study on Luzula - a genus with holokinetic chromosomes. Genome 47(2):246-256

Lu YJ, Kochert GD, Isenhour DJ, Adang MJ (1994) Molecular characterization of a strain-specific repeated DNA sequence in the fall armyworm Spodoptera frugiperda (Lepidoptera: Noctuidae). Insect Mol Biol 3(2):123-130

Luceño M, Vanzela ALL, Guerra M (1998) Cytotaxonomic studies in Brazilian Rhynchospora (Cyperaceae), a genus exhibiting holocentric chromosomes. Can J Bot 76(3):440-449

Maddison DR, Schulz KS. Tree of Life Web Project, Tree of Life Web Project

Maddox PS, Oegema K, Desai A, Cheeseman IM (2004) Holo'er than thou: chromosome segregation and kinetochore function in C. elegans. Chromosom Res 12(6):641-653

Malik HS, Henikoff S (2009) Major evolutionary transitions in centromere complexity. Cell 138(6):1067-1082

Mandrioli M, Bizzaro D, Manicardi GC, Gionghi D, Bassoli L, Bianchi U (1999) Cytogenetic and molecular characterization of a highly repeated DNA sequence in the peach potato aphid Myzus persicae. Chromosoma 108(7):436-442

Mandrioli M, Manicardi GC, Marec F (2003) Cytogenetic and molecular characterization of the MBSAT1 satellite DNA in holokinetic chromosomes of the cabbage moth, Mamestra brassicae (Lepidoptera). Chrom Res 11(1):51-56

Maruyama S, Matsuzaki M, Kuroiwa H, Miyagishima SY, Tanaka K, Kuroiwa T, Nozaki H (2008) Centromere structures highlighted by the $100 \%$-complete Cyanidioschyzon merolae genome. Plant Signal Behav 3(2):140-141

Meraldi P, McAinsh AD, Rheinbay E, Sorger PK (2006) Phylogenetic and structural analysis of centromeric DNA and kinetochore proteins. Genome Biol 7(3):R23

Mestrović N, Randig O, Abad P, Plohl M, Castagnone-Sereno P (2005) Conserved and variable domains in satellite DNAs 
of mitotic parthenogenetic root-knot nematode species. Gene 362:44-50

Mitreva M, Blaxter ML, Bird DM, McCarter JP (2005) Comparative genomics of nematodes. Trends Genet: TIG 21 (10):573-581

Monen J, Maddox PS, Hyndman F, Oegema K, Desai A (2005) Differential role of CENP-A in the segregation of holocentric C. elegans chromosomes during meiosis and mitosis. Nat Cell Biol 7(12):1248-1255

Mughal S, Godward MBE (1973) Kinetochore and microtubules in two members of Chlorophyceae, Cladophora fracta and Spirogyra majuscula. Chromosoma 44(2):213-229

Müller F, Walker P, Aeby P, Neuhaus H, Felder H, Back E, Tobler H (1982) Nucleotide sequence of satellite DNA contained in the eliminated genome of Ascaris lumbricoides. Nucleic Acids Res 10(23):7493-7510

Müller F, Bernard V, Tobler H (1996) Chromatin diminution in nematodes. Bioessays 18(2):133-138

Mutafova T, Dimitrova Y, Komandarev S (1982) The karyotype of four Trichinella species. Z Parasitenkd 67(1):115-120

Nagaki K, Kashihara K, Murata M (2005) Visualization of diffuse centromeres with centromere-specific histone $\mathrm{H} 3$ in the holocentric plant Luzula nivea. Plant Cell 17 (7):1886-1893

Niedermaier J, Moritz KB (2000) Organization and dynamics of satellite and telomere DNAs in Ascaris: implications for formation and programmed breakdown of compound chromosomes. Chromosoma 109(7):439-452

Nijalingappa BHM (1974) Cytological studies in Scirpus (Cyperaceae). Proc: Plant Sci 80(3):134-138

Oliver JH (1972) Cytogenetics of ticks (Acari: Ixodoidea). 8. Chromosomes of six species of Egyptian Hyalomma (Ixodidae). J Parasitol 58(3):611-613

Oliver JH (1977) Cytogenetics of mites and ticks. Annu Rev Entomol 22:407-429

Oliver JH, Tanaka K, Sawada M (1974) Cytogenetics of ticks (Acari: Ixodoidea). 14. Chromosomes of nine species of Asian haemaphysalines. Chromosoma 45:445-456

Paliulis LV, Nicklas RB (2004) Micromanipulation of chromosomes reveals that cohesion release during cell division is gradual and does not require tension. Curr Biol 14 (23):2124-2129

Paliulis LV, Nicklas RB (2005) Kinetochore rearrangement in meiosis II requires attachment to the spindle. Chromosoma 113(8):440-446

Panzera F, Pérez R, Hornos S, Panzera Y, Cestau R, Delgado V, Nicolini P (1996) Chromosome numbers in the Triatominae (Hemiptera-Reduviidae): a review. Mem Inst Oswaldo Cruz 91(4):515-518

Pazy B, Plitmann U (1994) Holocentric chromosome behaviour in Cuscuta (Cuscutaceae). Plant Syst Evol 191(1):105-109

Pérez R, Panzera F, Page J, Suja JA, Rufas JS (1997) Meiotic behaviour of holocentric chromosomes: orientation and segregation of autosomes in Triatoma infestans (Heteroptera). Chrom Res 5(1):47-56

Pérez R, Rufas JS, Suja JA, Page J, Panzera F (2000) Meiosis in holocentric chromosomes: orientation and segregation of an autosome and sex chromosomes in Triatoma infestans (Heteroptera). Chrom Res 8(1):17-25

Piotte C, Castagnone-Sereno P, Bongiovanni M, Dalmasso A, Abad P (1994) Cloning and characterization of two satellite
DNAs in the low-C-value genome of the nematode Meloidogyne spp. Gene 138(1-2):175-180

Post R (2005) The chromosomes of the Filariae. Filaria J 4:10

Procunier WS, Hirai H (1986) The chromosomes of Onchocerca volvulus. Parasitol Today 2(11):307-309

Ravi M, Shibata F, Ramahi JS, Nagaki K, Chen C, Murata M, Chan SW (2011) Meiosis-specific loading of the centromere-specific histone CENH3 in Arabidopsis thaliana. PLoS Genet 7(6):e1002121

Regier JC, Shultz JW, Zwick A, Hussey A, Ball B, Wetzer R, Martin JW, Cunningham CW (2010) Arthropod relationships revealed by phylogenomic analysis of nuclear protein-coding sequences. Nature 463(7284):10791083

Schneider MC, Zacaro AA, Pinto-da-Rocha R, Candido DM, Cella DM (2009) Complex meiotic configuration of the holocentric chromosomes: the intriguing case of the scorpion Tityus bahiensis. Chrom Res 17(7):883898

Schrader F (1935) Notes an the mitotic behavior of long chromosomes. Cytologia 6(4):422-430

Schvarzstein M, Wignall SM, Villeneuve AM (2010) Coordinating cohesion, co-orientation, and congression during meiosis: lessons from holocentric chromosomes. Genes Dev 24(3):219-228

Shakes DC, Wu JC, Sadler PL, Laprade K, Moore LL, Noritake A, Chu DS (2009) Spermatogenesis-specific features of the meiotic program in Caenorhabditis elegans. PLoS Genet 5 (8):e1000611

Sheikh SA, Kondo K (1995) Differential Staining with Orcein, Giemsa, CMA, and DAPI for comparative chromosome study of 12 species of Australian Drosera (Droseraceae). Am J Bot 82(10):1278-1286

Spakulová M, Králová I, Cutillas C (1994) Studies on the karyotype and gametogenesis in Trichuris muris. J Helminthol 68(1):67-72

Spence JM, Blackman RL, Testa JM, Ready PD (1998) A 169base pair tandem repeat DNA marker for subtelomeric heterochromatin and chromosomal rearrangements in aphids of the Myzus persicae group. Chrom Res 6(3):167175

Stimpson KM, Sullivan BA (2010) Epigenomics of centromere assembly and function. Curr Opin Cell Biol 22(6):772780

Streeck RE, Moritz KB, Beer K (1982) Chromatin diminution in Ascaris suum: nucleotide sequence of the eliminated satellite DNA. Nucleic Acids Res 10(11):3495-3502

Talbert PB, Bryson TD, Henikoff S (2004) Adaptive evolution of centromere proteins in plants and animals. J Biol 3 (4): 18

Tanaka T, Tanaka T (1977) Chromosome studies in Chionographis (Liliaceae): 1. On the holokinetic nature of chromosomes in Chionographis japonica Maxim. Cytologia (Japan) 42(3-4):753-763

Tarès S, Lemontey JM, de Guiran G, Abad P (1993) Cloning and characterization of a highly conserved satellite DNA sequence specific for the phytoparasitic nematode Bursaphelenchus xylophilus. Gene 129(2):269-273

Teschke C, Solleder G, Moritz KB (1991) The highly variable pentameric repeats of the AT-rich germline limited DNA in Parascaris univalens are the telomeric repeats 
of somatic chromosomes. Nucleic Acids Res 19(10):26772684

Vaarama A (1954) Cytological observations of Pleurozium schreberi, with special reference to centromere evolution. Ann Bot Soc Zool Bot Fenn 28:1-59

Viera A, Page J, Rufas JS (2009) Inverted meiosis: the true bugs as a model to study. Genome Dyn 5:137-156

White MJD (1973) Animal cytology and evolution. Cambridge University Press, Cambridge
Wignall SM, Villeneuve AM (2009) Lateral microtubule bundles promote chromosome alignment during acentrosomal oocyte meiosis. Nat Cell Biol 11(7):839-844

Wolfe SL, John B (1965) The organization and ultrastructure of male meiotic chromosomes n Oncopeltus fasciatus. Chromosoma 17(2):85-103

Zedek F, Bureš P (2012) Evidence for centromere drive in holocentric chromosomes of Caenorhabditis. PLoS One 7 (1):e30496 